\title{
O DISCURSO COMUNISTA NO CONSTRUTIVISMO RUSSO: A ARTE A SERVIÇO DA PROPAGANDA IDEOLÓGICA
}

\author{
João Flávio de Almeida \\ André Kettelhut
}

\begin{abstract}
Resumo
Ideologia é uma palavra que serviu de matériaprima para teóricos de muitas áreas do conhecimento, principalmente nas ciências humanas. Dentro dessas ciências, o filósofo francês Michel Pêcheux ajudou a desenvolver, foi membro do círculo, e também maior expoente do método chamado Análise do Discurso. Ele afirmava que é na ideologia que o indivíduo se torna sujeito; mas é na ideologia também que os discursos são (re)produzidos historicamente, fazendo o sentido parecer autêntico e verdadeiro. A partir dessa concepção de ideologia que nos propomos a olhar o movimento artístico construtivista russo, usado interpelar sujeitos pela máquina de propaganda do regime comunista soviético.
\end{abstract}

\section{Palavras-chave:}

Ideologia; Construtivismo Russo; Michel Pêcheux; Análise do Discurso; Comunicação.

\section{INTRODUÇÃO}

Utilizando do conceito de ideologia e do discurso ideológico trazidos por Michel Pêcheux, filósofo francês, o presente artigo se propõe a aprofundar, ao mesmo tempo, a questão da análise do discurso não-verbal, imagético, e sua aplicação em obras de um movimento artístico da Rússia soviética, o Construtivismo, que foi de extrema importância para a propagação ideológica comunista no período lênin-stálin. É nesse espaço de tempo também que a arte é forçada a migrar para o campo da propaganda, o que acabou por resultar em produções artísticas totalmente ideológicas.

Será utilizado, primeiramente, o método da pesquisa bibliográfica, que são procedimentos que visam a identificação das informações desejadas, a seleção das obras pertinentes ao tema e as respectivas anotações ou fichamentos

\section{Abstract}

Ideology is a word that served as raw material for theorists of many areas of knowledge, especially in the humanities. Within these sciences, the French philosopher Michel Pêcheux helped to develop, was member of the circle, and also greater exponent of the method called Discourse Analysis. He affirmed that it is in ideology that the individual becomes subject; but it is also in ideology that discourses are (re) produced historically, making sense to appear authentic and true. From this conception of ideology we set out to look at the Russian constructivist artistic movement, used to question subjects by the propaganda machine of the Soviet communist regime.

Keywords:

Ideology; Russian Constructivism; Michel

Pêcheux; Speech analysis; Communication.

das referências e dos dados (STUMPF, 2006, p. 51), já que a única maneira de entender um regime político já extinto é através dos estudos e das traduções daquela época. Também incorrerá na presente pesquisa o método do estudo de caso, que como dito pela autora Marcia Yukiko Matsuuchi Duarte (2006, p. 216, apud Yin), lidar-se-á com eventos que fogem do nosso controle e que seu foco se encontra em fenômenos contemporâneos que estão inseridos em algum contexto atual, como na reprodução de técnicas construtivistas russas por artistas pós-modernos. E por último, englobando os dois primeiros métodos, utilizaremos da análise do discurso francesa, que além das conceituações e explicações do próprio Michel Pêcheux, abordadas aqui, é simplificada como a apropriação dos sujeitos por formações discursivas que são anteriores a eles; logo, "(...) há enfâse no assujeitamento do emissor, que se 
expressaria mediante a incorporação de discursos sociais já instituídos: o religioso, o científico, o filosófico, (...) etc."(MANHÃES, 2006, p. 306) no caso desta pesquisa, seria o caso do discurso ideológico-artístico construtivista russo.

\section{COMUNISMO, MARXISMO E IDEOLOGIA}

O conceito "ideologia" ganhou muita força e importância no decorrer dos últimos quatro séculos, e, atualmente, vem sendo levantado e discutido frequentemente no caótico cenário político brasileiro. Pensadores célebres da história humana, como Kant ${ }^{1}$ e $\mathrm{Hegel}^{2}$, levantaram reflexões iniciais, não do termo em $\mathrm{si}$, mas de ideias paralelas que serviram de base para um aperfeiçoamento conceitual de seus contemporâneos. Feuerbach ${ }^{3}$, posteriormente, influenciado pela filosofia hegeliana, misturou o conceito da dialética histórica com seus ideais ateístas, tirando a importância da figura de Deus como regulador dos homens, afirmando que era na dialética histórica que o homem criou Deus como projeção de uma perfeição máxima que gostaria de ser e atingir.

Toda essa base conceitual-teórica foi estudada pela conhecida figura de Karl Marx ${ }^{4}$. Junto com Friedrich Engels, ambos publicaram o Manifesto Comunista, em 1848, onde pretendiam fazer frente, através da revolução do proletariado, o que chamaram de capitalismo, almejando a igualdade dos povos.

Sob o pretexto de uma ideologia que é sustentada pela luta de uma classe que domina, vulgo czares - ou seja, pela dialética histórica de Hegel transfigurada em luta de classes por Marx contra uma classe dominada, vulgo bolcheviques, Vladimir Lênin, intensificando seus estudos do direito e influenciado pelos ideais dos dois pensadores alemães, resolveu criar, através da revolução armada, o primeiro país comunista do mundo, em 1917. Assim nasceu a União das Repúblicas Socialistas Soviéticas, conhecida como URSS. ((EP3) Congresso Brasil Paralelo 2016).

Para o autor da teoria do discurso, que será apresentado a diante, esse conceito de ideologia é o que transforma os indivíduos em sujeitos, e seu trabalho (da ideologia) é apagar a distinção entre pensar e imaginar (PÊCHEUX, 1995, p. 170,176), por isso que "(...) todo sujeito é assujeitado no universalcomosingular "insubstituível" (PÊCHEUX,
1995, p. 171)." - em outras palavras, cada sujeito discursivo é retirado de seu nome próprio e posto em uma classe (ex: o sujeito João deixa de sê-lo para ser um sujeito militante comunista lêninista) que discursa, e, paradoxalmente, sentem-se donos e criadores das formações discursivas que empregam, ignorando o fato de estarem meramente reproduzindo discursos já enraizados na memória social. São insubstituíveis e autônomos. Esse é a consequência da ideologia.

\section{MICHEL PÊCHEUX E O DISCURSO}

Um país que produziu grandes filósofos, após a época de ouro da Alemanha, foi a França. É lá que nasce, em 1938, Michel Pêcheux, autor que ajudou no desenvolvimento da teoria do discurso. Em seus anos iniciais, o filósofo marxista concebeu os conceitos iniciais de uma teoria do discurso; em 1975, já na sua fase "madura", ele escreve a obra "Semântica e discurso: uma crítica da afirmação do óbvio", onde ele amplifica o conceito da ideologia através de uma base conceitual - base essa atravessada principalmente pelas ciências da Linguística (Saussure), Psicanálise (Freud) e o Marxismo (materialismo histórico-dialético). Esse foi o tripé no qual a Análise do Discurso francesa emergiu (ORLANDI, 2009, p. 19-20).

Quando se tem contato com Pêcheux em seus anos iniciais, é interessante observar como o autor refuta (e consequentemente enrijece as bases de sua teoria) os conceitos teóricos dos idealistas de seu tempo (embate marxista de classes: idealistas contra materialistas). Em um segundo momento, mais maduro, o autor abandona gradativamente alguns desses conceitos e aproxima-se da incompletude da linguagem. A análise da obra desta pesquisa encontra-se entre esses dois momentos.

Primeiramente, desmembrando e entendendo os conceitos pecheuxtianos, é necessário compreender que tudo está dentro da esfera da ideologia, e a matéria-prima utilizada para as análises é sempre a mesma: o discurso. De acordo com Orlandi, "o discurso é assim a palavra em movimento, prática de linguagem: com o estudo do discurso observa-se o homem falando" (ORLANDI, 2009, p.15). Os discursos podem ser vários e acabam em conjunto: formações discursivas.

Quando dizemos formações discursivas, faz-se indispensável regredir ao ponto da Linguística 
como área do conhecimento que constantemente era evocada para fora de seus domínios. Quando dissecada e analisada em sua unidade primordial, é indiscutível que o sistema da língua é o mesmo para o materialista e para o idealista, para o revolucionário e para o reacionário; contudo, eles não apresentam o mesmo discurso - ou seja, apesar dos discursos serem diferenciados, existe uma base comum entre eles (PÊCHEUX, 1995, p. 91). Esses processos discursivos não decorrem de imperfeições da linguagem, por isso não são um mero erro que pode ser evitado com alguma prática do indivíduo, mas sim, o contrário: esses "erros" são constitutivos da linguagem.

Acrescentando: o discurso é, em uma primeira instância, sempre intencional, e é por isso que apesar de o sujeito achar que ele é o dono e inventor do que diz, na verdade ele é afetado pelo encaixe sintático dos processos discursivos (PÊCHEUX, 1995, p. 99).

\section{MEMÓRIA}

Michel Pêcheux afirma que a ideologia é o que possibilita ao homem interpretar. Quando interpreta, este homem (sujeito) cai na ilusão do sentido (certa palavra designa certa coisa), e essa ilusão faz com que esse sujeito encontre naquele sentido um caráter autônomo, quando na verdade ele só o fez (produziu aquele sentido) através de formações discursivas anteriores (os sentidos o antecedem e mudam com o tempo). Esse efeito é o que determina o que Pêcheux chama de memória, e os vários discursos que se "cruzam" dentro dela são chamados de interdiscursos (ORLANDI, 2009).

O fato de que há um já-dito que sustenta a possibilidade mesma de todo dizer é fundamental para se compreender o funcionamento do discurso, a sua relação com os sujeitos e com a ideologia (ORLANDI, 2009, p. 32).

Essa memória também é chamada de memória social ou coletiva, ou seja, é o já-dito que possibilita o dizer, e é ela também que possibilita que os novos dizeres atualizem-se para coexistirem com novos acontecimentos discursivos (PÊCHEUX, 2010, p. 50-52).

A memória seria aquilo que, face a um texto que surge como acontecimento a ler, vem restabelecer os "implícitos" (quer dizer, mais tecnicamente, os pré-construídos, elementos citados e relatados, discursos-transversos, etc.) de que sua leitura necessita: a condição do legível em relação ao próprio legível (PÊCHEUX, 1999, p.52).

Quando se rompe uma memória com um novo sentido, produzimos o novo; caso se queira o efeito oposto, mantendo a memória coletiva para que se evite o novo, a estratégia é refletida na máxima do escritor inglês George Orwelll: "A história é escrita pelos vencedores". Os esquecimentos são partes constituintes da memória, e muitas vezes são intencionais - ou seja, retomando a frase de Orwell, quem escreve os registros históricos são sempre os vencedores, que selecionam formações discursivas de seus interesses e descartam (esquecimento) as demais. Mediante uma repetição constante, essas novas formações discursivas fragmentadas integram-se no novo todo (ilusório) da memória discursiva (PÊCHEUX, 2010).

\section{O NÃO-DITO E O DISCURSO NÃO-VERBAL}

Muitos conceitos são trazidos por Pêcheux ao longo de suas obras. O não-dito complementa o discurso e aumenta a sua abrangência - e consequentemente as possibilidades de análise. Nestes termos, o não-dito (esquecimento, silenciamento etc.) aparece como aquilo que fura a totalidade da memória.

Não se trata de pretender aqui que todo discurso seria como um aerólito miraculoso, independente das redes de memória e dos trajetos sociais nos quais ele irrompe, mas sublinhar que, só por sua existência, todo discurso marca a possibilidade de uma desestruturação-reestruturação dessas redes e trajetos. (PÊCHEUX, 2008, p.56).

O não-dito faz parte do dito, ou verbal. Portanto, significa igualmente nas formações discursivas. Dentro do não-dito, como explicado por Orlandi (2009, p.82), temosopressupostoeosubentendido, onde o primeiro deriva da instância da linguagem e o segundo da instância do contexto. Em outras palavras, só existe um pressuposto por que há um suposto (ex: "ele parou de fumar". Só é possível parar de fumar porque anteriormente havia ali o hábito de fumar), enquanto o subentendido, além de incerto, depende dos fatores contextuais em que a formação discursiva está inserida (não é possível saber quais circunstâncias o levaram a parar de fumar. Pode ser fatores de consciência com o próximo, fatores de saúde, etc).

$E$ é neste embate entre pressupostos e subentendidos que se sustenta o embate entre $o$ 
"mesmo" e o "novo", vistos nas figuras de linguagem "paráfrase" e "polissemia", respectivamente.

Os processos parafrásticos são aqueles pelos quais em todo dizer há sempre algo que se mantém, isto é, o dizível, a memória. A paráfrase representa assim o retorno aos mesmos espaços de dizer. Produzem-se diferentes formulações do mesmo dizer sedimentado. A paráfrase está do lado da estabilização. Ao passo que, na polissemia, o que temos é o deslocamento, a ruptura de processos de significação. Ela joga com o equívoco. (ORLANDI, 2005, p. 36)

A memória discursiva se constrói, portanto, em consonância com o silenciamento e o esquecimento. Só é possível uma memória discursiva por que "nem tudo fica na memória discursiva". Dito de outra forma, a estrutura da memória discursiva é, ela mesma, repleta de furos, derivas e descontinuidades que impedem sua plenitude.

Uma memória não poderia ser concebida como uma esfera plena, cujas bordas seriam transcendentais históricos, e cujo conteúdo seria um sentido homogêneo, acumulado ao modo de um reservatório: é necessariamente um espaço móvel de divisões, de disjunções, de deslocamentos e de retomadas, de conflitos de regularização. Um espaço de desdobramentos, réplicas, polêmicas e contra-discursos (PÊCHEUX, 1999, p.56).

O fato da análise do discurso considerar que os sentidos são produzidos para além do texto, possibilita uma análise de sinais, códigos visuais, códigos sonoros, texturas, luz e sombra, enquadramento, etc. - em suma, características não-verbais. Sendo assim, "a interpretação do não-verbal se efetiva por meio do efeito de sentidos que se institui entre o olhar e a imagem, a partir das formações sociais em que se inscrevem tanto o sujeito-esteta (que é o sujeito que enuncia pictoricamente) da imagem não-verbal, quanto o sujeito que a tem diante de si" (CARVALHO, 2010, p.4). Dentro do Construtivismo, o não-dito exerceu um papel fundamental.

\section{CONSTRUTIVISMO RUSSO}

No início do século XX, a Rússia foi devastada pela guerra civil. $O$ exército vermelho dos bolcheviquis emergiu vitorioso sob o comando de Lênin. Durante esse período, floresceu na URSS uma arte experimental, que inicialmente, sob uma forma totalmente abstrativa geométrica e com cores primárias, foi criada sob o nome de Suprematismo por Kasímir Maliévitch (1878-1935). O artista rejeitava completamente a arte como uma prática com finalidade, mas sim como uma expressão do sentimento, sem objetivar nenhum valor prático ou ideia (MEGGS, 2009, p. 373-374). Contudo, houveram artistas que apresentaram o ponto de vista contrário, alegando que a arte agora deveria servir para os propósitos sociais do comunismo. Para isso, abandonaram as belas artes, como a pintura e a escultura, tornando-se mais próximos de serem designers e publicitários do que artistas. Os nomes que edificaram o movimento contrário ao Suprematismo, chamado de Construtivismo, foram Aleksandr Mikhailovich Rodchenko e Vladimir Evgrafovič Tatlin.

Eventualmente, questões políticas atingiram os artistas, e não tardou para que o sujeito-artista soviético se tornasse sujeito-propagandista soviético. Essa migração não ocorreu por acaso, apesar de artistas como Rodchenko, El Lissítzky e Tátlin terem se adaptado de bom grado à causa (muito provavelmente pela possibilidade do designer de exercer sua atividade artística, usufruindo de uma liberdade experimental, ao mesmo tempo que em contribuíam com a causa comunista), mas sim, em sua maior parte, por pressões governamentais, principalmente quando Lênin morre e Stálin chega ao poder. Na verdade, o florescimento de artes experimentais como o Suprematismo foram toleradas enquanto problemas políticos maiores eram resolvidos. A partir de 1922, iniciou-se uma intensa perseguição e diversos artistas foram acusados de serem "cosmopolitanistas capitalistas", o que resultou no desaparecimento - muitos enviados para campos de concentração, como Gustav Klútsis, o mestre da fotomontagem ou simplesmente foram esquecidos pela sociedade e morreram na miséria e no ostracismo, como o próprio Maliévitch (MEGGS, 2009, p. 384). Os designers eram os novos porta-vozes do movimento social, ao passo em que os artistas aos moldes clássicos foram sendo sufocados. Stálin havia deixado bem claro: não haveria espaço para quem não servisse ao propósito prático da propaganda ideológica comunista.

\section{CORPUS: EL LISSÍTZKY}

El (Lazar Márkovitch) Lissítzk (1890 - 1941) foi o maior expoente do construtivismo russo. 0 construtor (assim ele se autodenominava ao invés de designer) via na Revolução Russa de 1917 
um novo começo para a humanidade, e foi esse idealismo dos princípios comunistas que o levou a enfatizar o design gráfico, e assim foi passando gradativamente da experiência estética pessoal para a corrente da vida em comunidade (MEGGS, 2009, p. 377).

Dentro as muitas obras produzidas por El Lissítzky, uma das mais impactantes foi o seu livro infantil "Um Conto Suprematista de Dois Quadrados em 6 Construções" (2014 - tradução livre), de 1922. Apesar de ser uma obra do período Suprematista, seu forte simbolismo foi levado adiante pelo próprio Lissítzky no período construtivista, além do fato de ser direcionado ao público infantil, que por si só já é um discurso ideológico.

A análise do não-verbal imagético será feita via significação, objetivando como foram produzidos os sentidos e como os elementos se unem para produzir significações. Do ponto de vista do sujeito, CARVALHO (2010) diz:

É fato que a imagem depende da produção de um sujeito, isto é, passa por alguém que a produz ou reconhece. No entanto, os sujeitos envolvidos na produção e recepção do discurso (a obra) não dominam toda significação da imagem, levandose em consideração que discurso é marcado por tensões, conflitos socioideológicos que são constitutivos da formação social (p. 7).

Desde a primeira página do livro, assim como qualquer obra construtivista, percebe-se a palheta de cores vermelha-branco-preta (Figura 1).

Essas cores não eram escolhidas ou utilizadas ao acaso ou aleatoriamente - conceitualmente, dentro da análise do discurso, foram possibilitadas novas significações (para as cores, nesse caso) devido a incompletude da linguagem. Em qualquer livro teórico sobre design gráfico ou sobre o movimento construtivista russo em si, é possível identificar que a cor vermelha era a representação do exército bolchevique. O preto, cor dos corruptos, era associada ao clero e aos capitalistas. O branco, por fim, era a cor do exército conversador (czares).

Aqui, o autor diz que os dois quadrados voavam longe da Terra e a observavam a distância (Figura 2). Entendendo a simbologia cromática citada anteriormente, é possível levantar pontos interessantes aqui: o planeta é vermelho, mas as construções acima dele são pretas e brancas. Isso pode dizer (e a criança é levada a entender) que a Terra sempre foi comunista e igualitária, mas que ela estava sendo oprimida pelos ideais e atos capitalistas que imperavam sobre ela (o branco das construções associa-se ao preto para entender que os capitalistas eram tão perversos quanto os czares, oprimindo a sociedade outrora livre).

Aqui o sujeito-esteta não objetivou deixar subentendida a mensagem; ele o fez muito claramente. Utilizando o texto como apoio (um preto alarmante), a desordem visual reflete como o exército branco e o capitalismo destruíam a sociedade (Figura 3). Nesta página não há uma unidade, os elementos flutuam e o caos impera, já que o vermelho (da ordem e justiça comunista) está ausente. Um elemento que também vale a pena ser citado é a tipografia: as formas negritas que contrastam com as que não são (conhecidos como lights), podem ser entendidas como entonações de leitura - por isso, as partes mais "dramáticas" são associadas aos pesos das fontes, como o negrito. Além disso, a própria disposição do texto reflete a ideia de cada página (nesse caso, a desordem).

Quando o quadrado vermelho colide com o planeta corrompido, tudo se quebra (Figura 4). Muitas coisas podem estar subentendidas aqui: o sujeito-esteta utilizou da hierarquia visual das formas, pondo o quadrado vermelho maior do que as geometrias, significando que o comunismo era mais forte e mais consistente que qualquer produção (construção) capitalista. O contraste visual também é forte, já que cores neutras (talvez essa também tenha sido uma das causas da escolha delas no início do movimento) perdem importância diante de cores quentes e vibrantes, como o vermelho. 0 texto também pode significar de uma maneira simples e objetiva: "um golpe, tudo se quebra"; ou seja, não são necessários vários golpes para se derrubar o capitalismo, mas somente um. O sujeito-leitor é levado a interpretar a fragilidade e inconsistência de um regime capitalista.

Mais um exemplo de trabalho ideológico que passa longe do subentendido: o texto é claro, e diz que "sobre o preto, o vermelho se estabeleceu claramente" (Figura 5). As construções, diferente de antes, agora são mais simétricas e ordenadas, transparecendo a ordem social produzida pelo comunismo. 


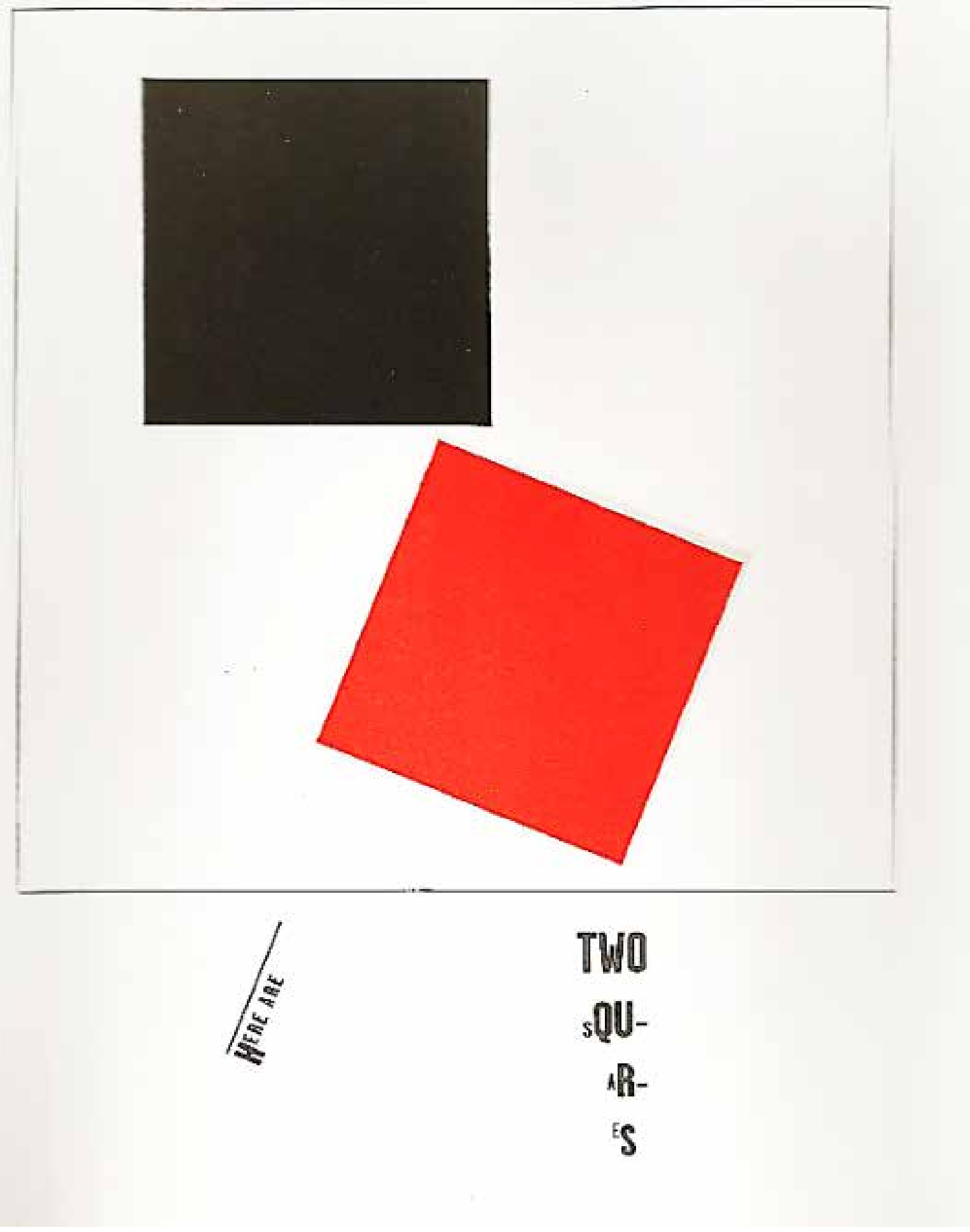

Figura 1 - página 1 de "Um Conto Suprematista de Dois Quadrados em 6 Construções" (2014 - tradução livre), de 1922.

Um outro ponto interessante está presente aqui: o quadrado preto capitalista originalmente estava voando junto com o vermelho. Isso poderia ser traduzido como a ajuda (possivelmente financeira) que o exército bolchevique teve de possíveis empresários ou de corporações privadas clandestinas para derrubar o sistema czarista. Porém, como ambos os regimes não podem 

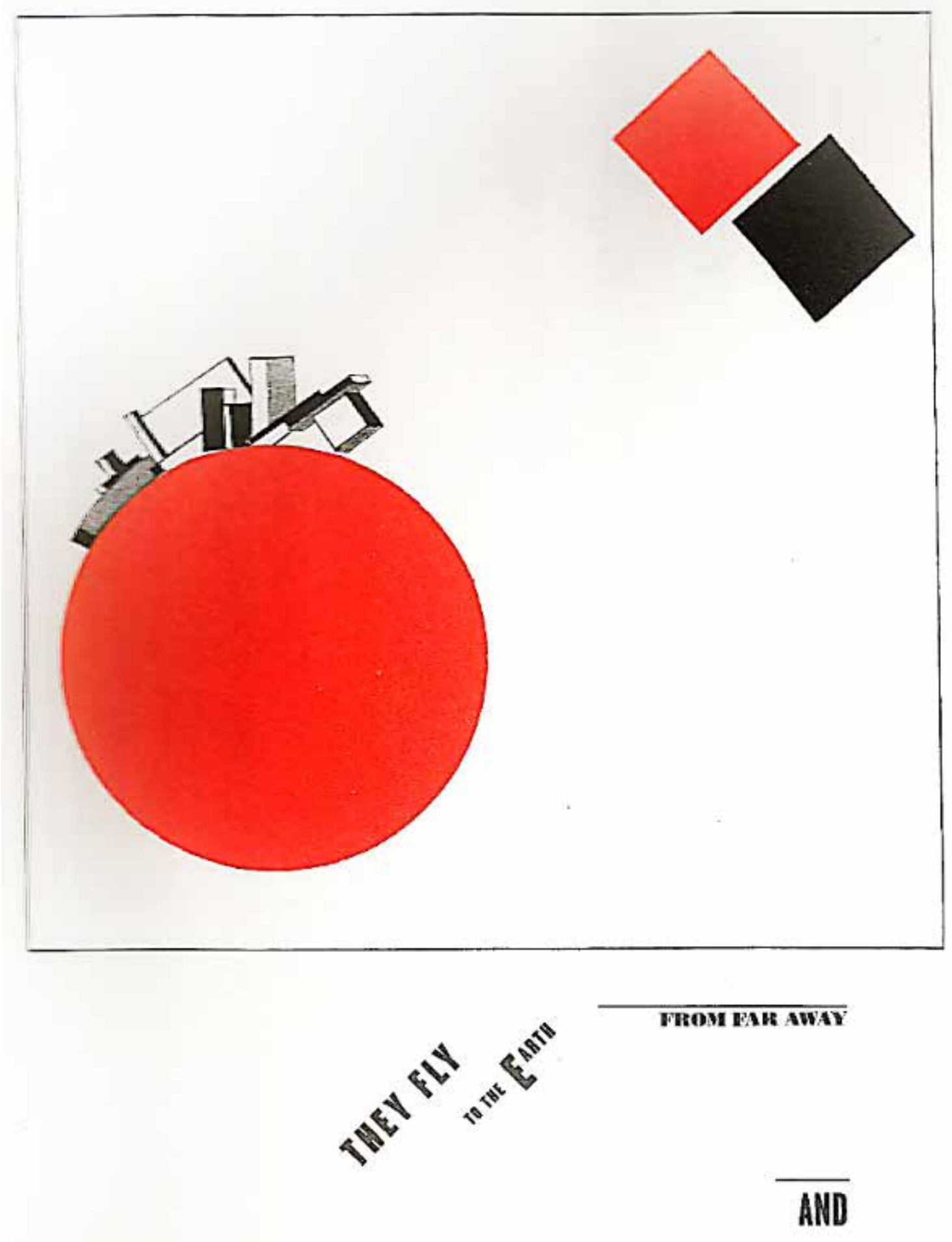

Figura 2 - página 7 de "Um Conto Suprematista de Dois Quadrados em 6 Construções" (2014 - tradução livre), de 1922.

coexistir ideologicamente, eventualmente os vermelhos resgataram os brancos remanescentes que simpatizaram pela proposta ideológica comunista, e, agora sendo todos vermelhos, juntos sufocam e "constroem" seu governo sobre o quadrado preto, que outrora os ajudou a derrubar os brancos. O sujeito-leitor é interpelado fortemente aqui, pois é levado a entender que por 


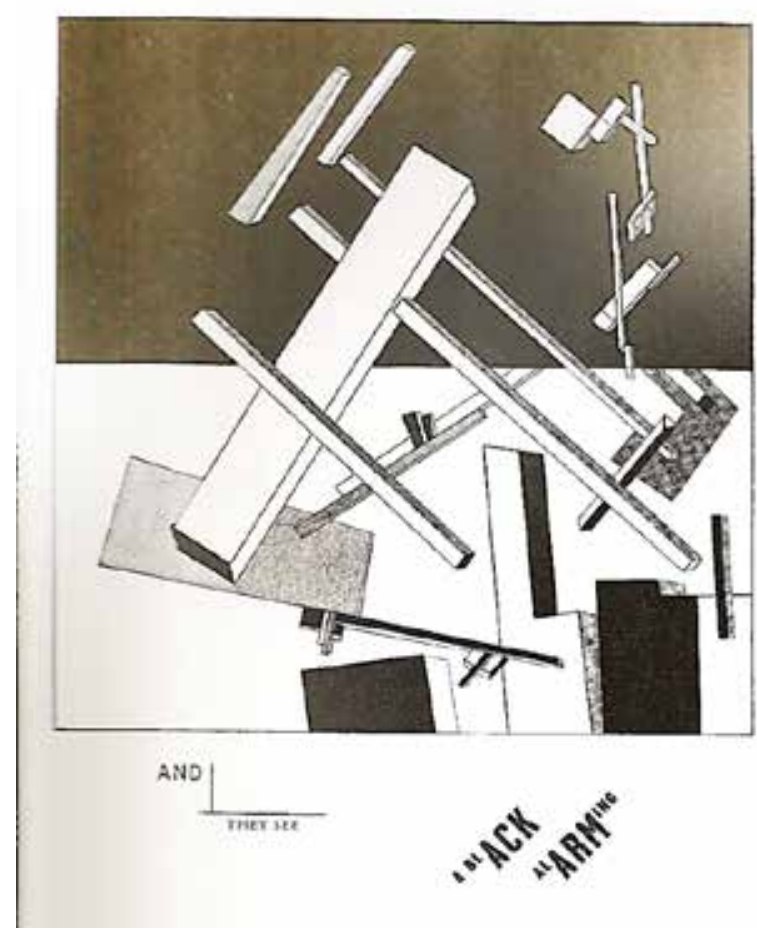

Figura 3 - página 9 de "Um Conto Suprematista de Dois Quadrados em 6 Construções" (2014 tradução livre), de 1922.

maior que seja a necessidade de uma parceria com o livre mercado, os capitalistas não são confiáveis, e eventualmente a ideologia comunista deve prevalecer acima de qualquer acordo.

Na última página, o sujeito-esteta encerra a obra de maneira exemplar: o preto foi descartado, e o vermelho encontra-se dentro do círculo. Isso pode significar que o comunismo havia sido absorvido (ou aceito) pelo planeta (Figura 6). A ordem visual poderia ser traduzida no aspecto de que somente com o vermelho é que tudo passou a perfeita simetria. Também é possível subentender que não houve espaço na ordem final das coisas para o capitalismo, já que a cor preta não está presente. UNOVIS, grupo de artistas russos daquele período, está dentro do círculo e fora do quadrado, talvez significando que eles eram os precursores - ou a vanguarda - da nova ordem (ideal) mundial. Apelando a hierarquia visual, de fora para dentro, o grupo é mais importante que o quadrado vermelho (o comunismo), mas menos importante do que o círculo (a Terra) (em uma análise mais subjetiva,

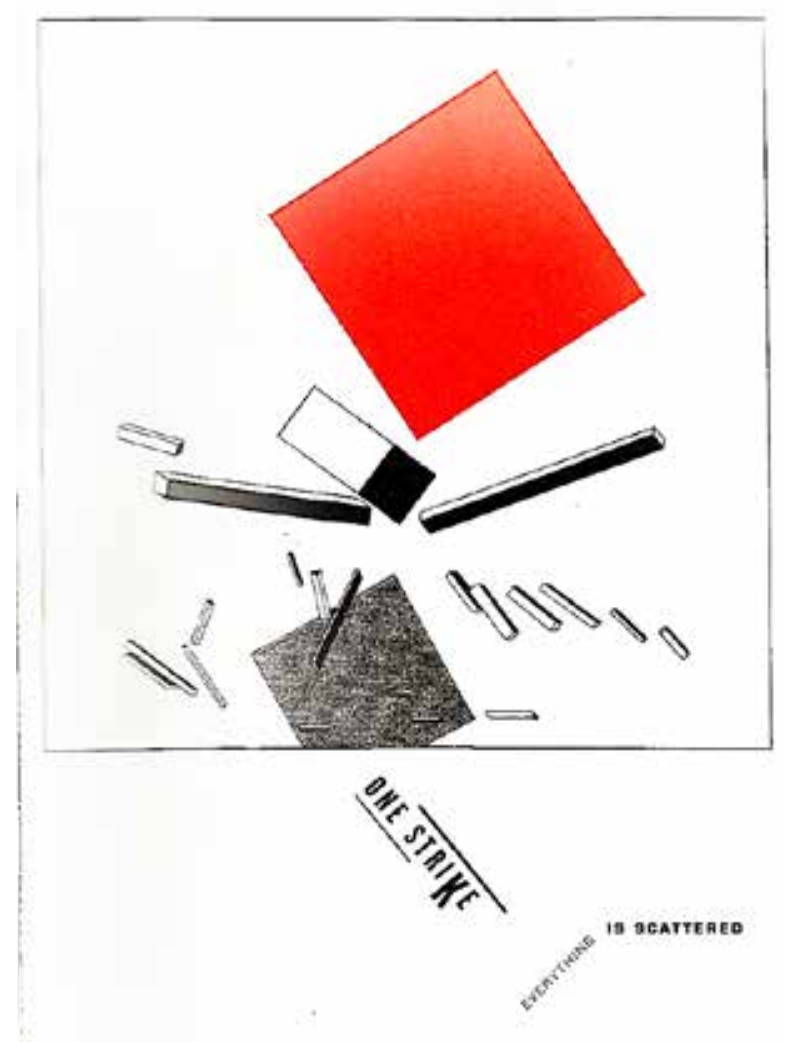

Figura 4 - página 11 de "Um Conto Suprematista de Dois Quadrados em 6 Construções" (2014 tradução livre), de 1922.

talvez o sujeito-esteta quisesse significar que o comunismo era disseminado através deles, uma vez que eles que eram os porta-vozes do movimento; em uma esfera maior, jamais existiria qualquer tipo de ideologia, pretensões, debates, intelecto, seres humanos, etc, se não houvesse o planeta para nos manter).

Assim, importa ressaltar o papel duplo da cor branca nessa obra, já que em alguns momentos, ela significa o exército branco; em outros, como a proposta do construtivismo russo era o contraste visual, ela serve meramente para exaltar os demais elementos pretos e vermelhos (como nessa última página).

\section{CONCLUSÃO E CONSIDERAÇÕES FINAIS}

O que se percebe estudando Pêcheux é uma teoria materialista do discurso que mostra a incompletude das formações discursivas, permitindo que se crie novos sentidos, através das rupturas que constituem a memória coletiva. Por isso que o autor diz que somos meros sujeitos que somente significam porque somos interpelados 


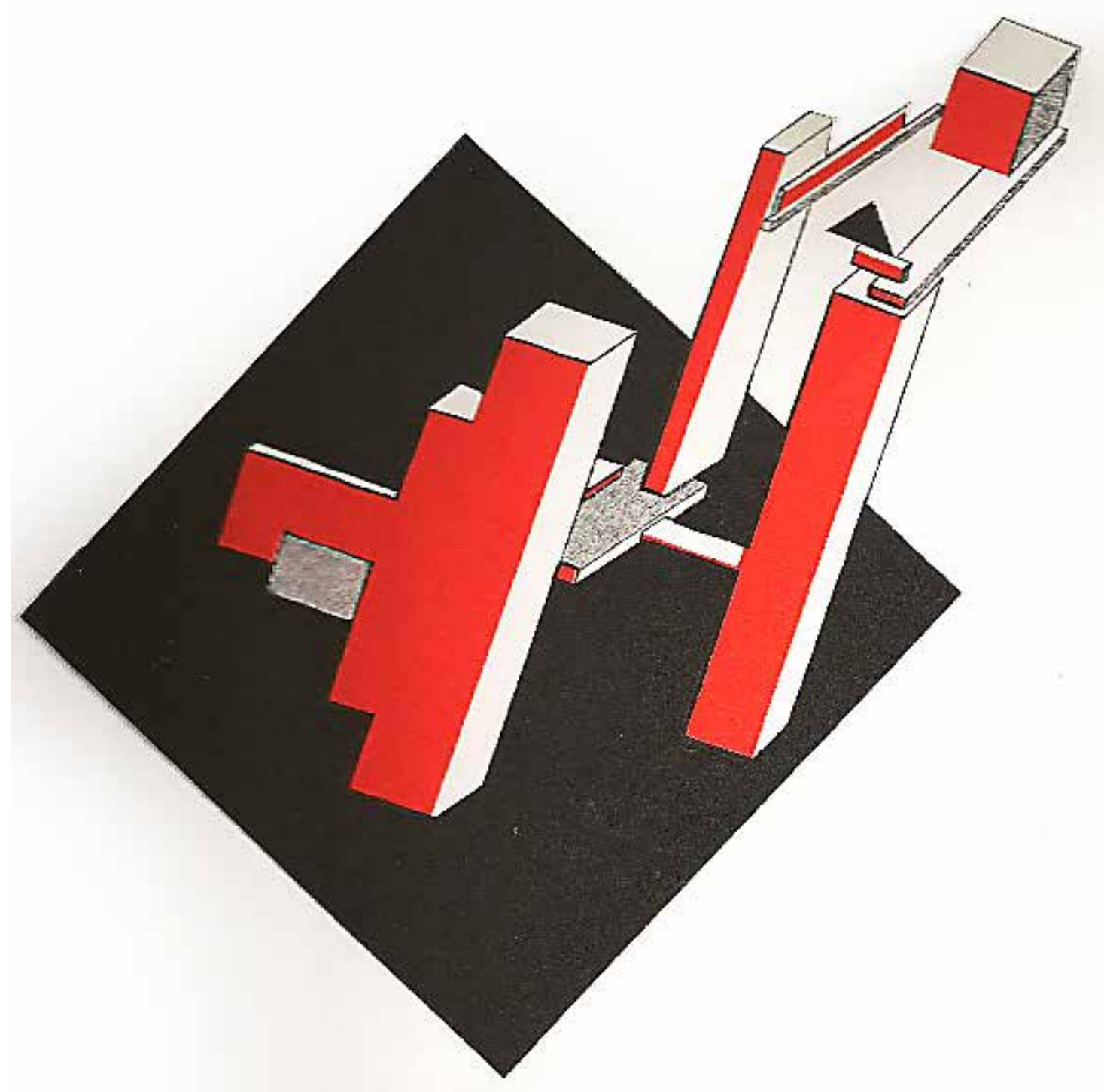

11) 0/ THE B LACK

\section{IS ESTABLISHED}

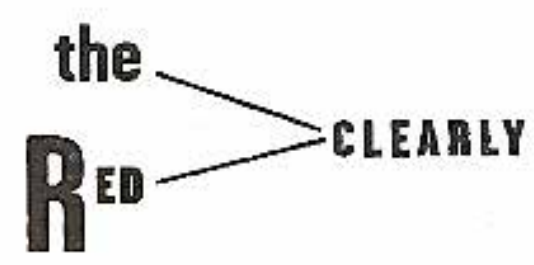

Figura 5 - página 13 de "Um Conto Suprematista de Dois Quadrados em 6 Construções" (2014 - tradução livre), de 1922. 

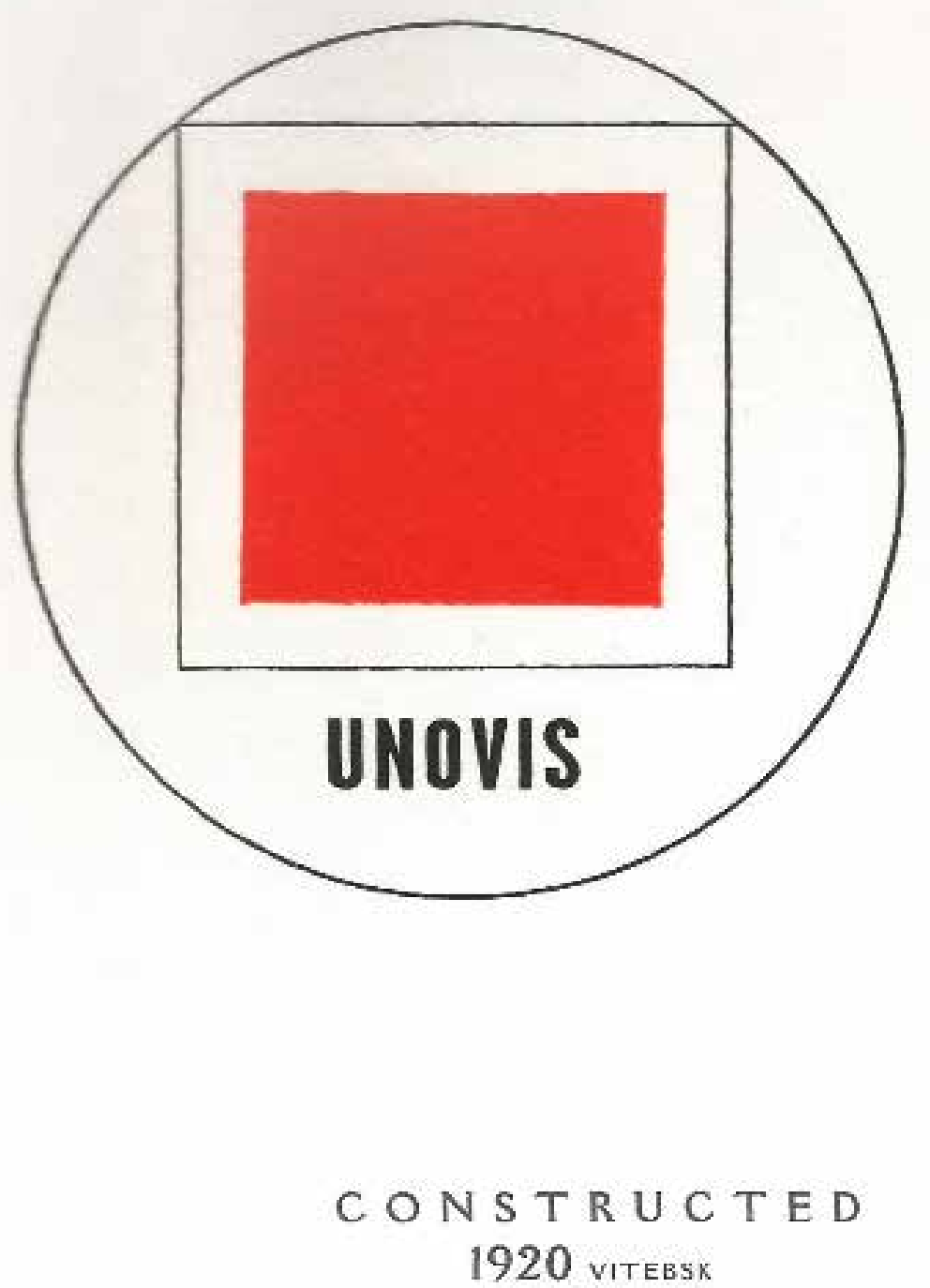

Figura 6 - página 17 de "Um Conto Suprematista de Dois Quadrados em 6 Construções" (2014 - tradução livre), de 1922.

pela ideologia ao utilizarmos formações discursivas que nunca foram nossas - a ilusão que os sujeitos têm de sua autonomia é consequência do efeito ideológico, e não a causa dela.

Todos esses conceitos, quando entrelaçados, junto com o esquecimento de parte da memória social, são muito bem ilustrados em vários momentos pós-modernos. A banda escocesa Franz Ferdinand, por exemplo, é um bom caso a ser analisado, já que algumas artes de seus álbuns são claramente inspiradas pelo movimento construtivista russo (duas capas mais especificamente: "Franz Ferdinand" de 2004, e "You Could Have It So Much Better", de 2005), além de o clipe da famosa "Take Me
Out" ser completamente ambientado em moldes construtivistas. Essa "apropriação do discurso" é interessante do ponto de vista pecheuxtiano, já que o caráter ideológico do movimento artístico russo foi sofrendo um esquecimento, ao ponto em que está sendo usado, em nosso tempo, como mera ilustração (estética artística fortemente combatida pelos construtivistas) para a venda (prática capitalista) de um produto pertencente a um grupo, e não ao Estado (princípio contrário ao socialismo ou comunismo). 


\section{NOTAS}

01. Para mais detalhes, ler: KANT, Immanuel. Crítica da Razão Prática. Petrópolis: Vozes, 2016. 240 p. Título original: Kritik der Praktischen Vernunf, 1788.

02. Para mais detalhes, ler: HEGEL, Gwf. Fenomenologia do Espírito. 4. ed. Petrópolis: Vozes, 2011. 552 p. Título original: Phänomenologie des Geistes, 1807.

03. Para mais detalhes, ler: FEUERBACH, Ludwig. A Essência do Cristianismo. Petrópolis: Vozes, 2013. 344 p. Título original: Das Wesen des Christentums, 1839.

04. Para mais detalhes, ler: MARX, Karl. o Capital: crítica da economia política: Livro I: o processo de produção do capital. 25. ed. Rio de Janeiro: Civilização Brasileira, 2008. 574 p. Título Original: Das Kapital: Kritik der Politischen Ökonomie Bush 1: der Produktionsprozess de Kapital, 1867. Tradução de: Reginaldo Sant'Anna.

\section{REFERÊNCIAS}

PÊCHEUX, Michel. Discurso: Estrutura ou Acontecimento. Tradução de Eni Pulcinelli Orlandi. Campinas: Pontes, 1990. 68 p.

PÊCHEUX, Michel. Semântica e Discurso: Uma Crítica À Afirmação Do Óbvio. Tradução de Eni Pulcinelli Orlandi [et all]. 2.ed. Campinas: UNICAMP, 1995. 317 p.

DUARTE, Jorge; BARROS, Antonio. Métodos e Técnicas de Pesquisa em Comunicação. 2 ed. São Paulo: Atlas, 2006. 380 p.

ORLANDI, Eni Puccinelli. Análise de Discurso: Princípios e Procedimentos. 8 ed. Campinas: Pontes, 2009. $100 \mathrm{p}$

LISSÍTZKY, Lazar Márkovitch. A suprematist Tale of Two Squares in 6 Constructions [Um Conto Suprematista de Dois Quadrados em Seis Construções]. Londres: Tate Publishing, 2014. 18 p. Tradução de: Christina Lodder.

(EP3) A Raiz do Problema - Como chegamos aqui? [Oficial]. Direção de Brasil Paralelo. Produção de Brasil Paralelo. Realização de Brasil Paralelo. Porto Alegre, Rs: Brasil Paralelo, 2016. (44 min. e 35 seq.), son., color. Disponível em: <https:// www.youtube.com/watch?v=PFV3AW5IIgl $>$. Acesso em: 23 abri. 2017.

CARVALHO, Sônia de Fátima Elias Mariano. "Palavra pintada: o texto não-verbal e sua discursividade estética". Disponível em: https://periodicos.ufsm.br/revislav/article/ view/2164/1362. Acesso em 20/04/2017.

\section{SOBRE OS AUTORES}

João Flávio de Almeida é Doutor pelo programa pós-graduação em Ciência, Tecnologia e Sociedade, UFSCar (2015-2018). Pesquisa em Filosofia da linguagem e Teoria do Conhecimento a partir de Michel Pêcheux. Título da tese: Para uma epistemologia da errância: erro, hiância e ciência em Michel Pêcheux. 2. Mestre pelo programa de Ciência, Tecnologia e Sociedade, UFSCar (20122013). Pesquisa em Análise do Discurso Francesa (Michel Pêcheux) e Filosofia (Sartre). Título da dissertação: 0 discurso da obsolescência: o velho, o novo e o consumismo. 3. Graduação em Comunicação Social pelo Centro Universitário Barão de Mauá (2007). 4. Docente nos cursos de Jornalismo/Publicidade e Propaganda na Universidade de Ribeirão Preto (UNAERP).

André Kettelhut é Possui graduação em Design de Games pela Universidade Anhembi Morumbi(2013). Atualmente é Estagiário da Universidade de Ribeirão Preto. Tem experiência na área de Comunicação, com ênfase em Comunicação Visual. 